\title{
Keeping Company with Seabright
}

\author{
Geoffrey Brennan
}

Received: 25 July 2011/Accepted: 25 September 2011/Published online: 11 April 2012

(C) Konrad Lorenz Institute for Evolution and Cognition Research 2012

\begin{abstract}
According to Paul Seabright, "the unplanned but sophisticated coordination of modern economies is a remarkable fact that needs an explanation." In this paper, I explore what is remarkable about modern economies and investigate what Seabright identifies as the aspect "that needs an explanation." Essentially, Seabright is interested in the fact that modern economies require a great deal in the way of trustworthy behavior (and trust) in order to function welland these trust relations must operate specifically among "strangers"! The puzzle for him is how relations of trust (and trustworthiness) among strangers could conceivably have arisen from our tribal evolutionary past. I raise several queries about his diagnosis of this puzzle and of his answer to it.
\end{abstract}

Keywords Economy $\cdot$ Evolution $\cdot$ Strangers $\cdot$ Trust

\section{Introduction}

Paul Seabright's (henceforth PS) The Company of Strangers is a fascinating and highly readable book. It shows a

Colloquium on Paul Seabright's The Company of Strangers.

G. Brennan ( $\square)$

School of Philosophy, Research School of Social Sciences

(RSSS), Australian National University,

Canberra, ACT, Australia

e-mail: Geoffrey.Brennan@anu.edu.au

G. Brennan

Department of Philosophy, University of North Carolina, Chapel Hill, NC, USA

G. Brennan

Department of Political Science, Duke University,

Durham, NC, USA totally impressive - and to me admirable-disciplinary breadth, including economics (and particularly the economics of institutional design), evolutionary history, psychology, criminology, and anthropology. It is full of interesting speculations, little puzzles (as well as some big puzzles), and fascinating asides.

Here is a tiny example of the latter. It represents nothing more than a throw-away line or two in the PS narrative, but it is clever and arresting and serves to exemplify something of the character of the book. The example revolves around the issue of how rational induction procedures can operate to produce false beliefs. Here's how it goes. Suppose that half the airplanes that fly are empty and that the other half are completely full. As a result, all passengers report in total honesty on the basis of their experience that all planes are full-and the accumulation of that testimony across the whole sample of passengers appears to give compelling evidence that what they say is true. But by construction, it is false.

What is involved here is a neat "model" of selection bias in induction procedures. It shows that, in some cases, what everyone has maximal evidentiary warrant for believing is systematically untrue. Perhaps the example is well known in certain circles; but it was new to me. And though, as far as I can see, it plays no great role in the larger PS story, I found it striking; and typical of the kinds of interesting aperçus with which the book is littered.

My chief concern here, however, is with PS's larger agenda - and more particularly with some lack of clarity as to what his central thesis actually is, and how it connects with the evidence that I see him as offering.

Here is what PS says by way of a summary introduction: "the unplanned but sophisticated coordination of modern economies is a remarkable fact that needs an explanation" (p. 12). 
No economist is likely to disagree with this proposition as it stands. But in my view, it needs some unpacking-and unpacking specifically in relation to two questions.

First, what exactly is it about "modern economies" that is "remarkable"? And second, is what makes modern economies "remarkable" the same thing that "needs an explanation"? In other words, what precisely is the puzzle that PS sees at the center of the phenomenon he is trying to explain?

I think it is clear that PS's chief interest here lies in the emergence of trust - and specifically of trust in strangerswhich he sees as a necessary requirement for the successful operation of "modern economies." More especially, he is interested in the connection between such trust and what our species carried into "modern times" (say from 10,000 $\mathrm{BC}$ onwards) from the period of our earlier evolutionary past.

In the discussion of this big canvas picture, I seek to do three things: (1) to indicate what seems to me to be "remarkable" about modern economies, and more generally about the "post-evolutionary" history of the human species; (2) to indicate the role that trust specifically plays in that history; and (3) to draw attention to what I detect as some ambiguity in the story PS offers concerning the connection between trust in strangers and our evolutionary heritage.

\section{Remarkable?}

The "sophisticated coordination of modern economies" is a "remarkable fact" mainly, I think, in the light of something yet more remarkable-namely, those economies' amazing productive capacity. Economists since the time of Adam Smith ([1776] 1981) have seen markets as a distinctive force for mobilizing the gains from human cooperation-gains that, as Smith observed, we probably would not recognize but for the fact of their delivery. Smith's is not a distinctive view among economists: it is something that PS and I and for that matter Karl Marx all share; though as PS remarks at one point, even Adam Smith would have been hard-pressed to imagine just how far the processes that he observed would take us in the 250 years since he wrote.

Consider. How much better off is the average person in the West (the UK, for example) now as compared with, say, 1700? This is a question we economists occasionally pose to our undergraduates - with the predictable array of random answers. Best estimates indicate something of the order of 16-fold (see McCloskey (2006), following Maddison (2001)). To see how significant this is, imagine that global warming served to reduce material well-being in the UK to its 1700 level: most of us would regard a reduction in our material well-being to one 16th of its current level as unimaginably catastrophic, and this notwithstanding the fact that the standard of living in the UK in 1700 was not too bad by long-term historical standards.

Or consider the increase in life expectancy in the West since, say, 1900. It has been increasing at the rate of slightly more than 2 years every decade over the century. That is, those who are dying now have had, on average, a quarter of a century more living than their ancestors a century ago. In the earlier period much of the increase in expected longevity was a result of reduced infant mortality; but since 1950, it has mainly been the result of simply longer life. On average, we are simply living rather longer and very considerably better than at any time in human history. Of course with the growth in world population, the absolute number of poor persons (say those living on less than one dollar per day) has remained very high. However, per capita gdp across the globe has increased about eightfold since 1820, despite "global poverty." Estimates suggest that world per capita gdp rose only $50 \%$ from $1000 \mathrm{AD}$ to 1820 .

This is made all the more remarkable in that the improvement in average living standards has gone alongside spectacular increases in human population. Current estimates indicate that in 10,000 $\mathrm{BC}$, the world's human population was around 4 million. Over the next 5,000 years it rose by about another 1 million, but then started to increase more quickly and by the birth of Christ was 170 million (a 30-fold increase over that second 5,000 year period). By 1900, it had risen by a factor of just less than ten and in the next century by a further factor of 6 . To focus the contrast, in the 2,000 years before Christ, the world's population had increased by a factor of five; in the 2,000 years after Christ it rose by a factor of 60, almost doubling in the last 35 years.

Of course, it is no great surprise that total population would more or less track total world production: that is just Malthusian logic. It is, I suppose, the logic of the locust plague - and at least some ecologists seem to regard the human case in somewhat the same terms. But the human case seems distinctive in several crucial respects. For one thing, as already noted, the vast increase in human numbers has been associated with a considerably greater increase in total productive capacity. Malthus could explain the growth in population given the growth in aggregate production; but he had no explanation for the underlying increase in production itself.

I do not know whether with other species the notion of quality of life (average well-being) makes much sense, or whether other species (apart from those parasitic on human "material progress") have enjoyed significantly increased life span. But it does seem clear to me (as it does to PS) that in sheer evolutionary terms, the tiny episode of human 
history is indeed utterly remarkable — and does call for an explanation.

Smith's account emphasizes the emergence of market institutions. But his particular story is distinctive in a number of respects; and in order to place PS's gloss on the Smithian story in context, it may be useful to say something about Smith's distinctiveness.

Let me re-state briefly what I take to be the relevant piece of Smith's argument. ${ }^{1}$

(1) There are huge gains to be made from specialization (including specialization in the making of "machines" and related "speculation"- - though Smith's prime example is the pin factory where he notes productivity increases of the order perhaps of 4,800-fold!).

(2) Specialization is made possible by market exchange: since man cannot live by pins alone, it is only when agents can exchange their products that specialization becomes possible.

(3) The extent of specialization is limited by the "extent of the market." If the size of the market were doubled, the degree of specialization would predictably increase, with correspondingly increased consumption per head of all goods after exchange.

Now, the idea of the division of labor was hardly new. Plato, Aristotle, and derivatively St. Paul, all had a clear conception of the division of labor and the specialization possibilities that markets allowed. In that sense, Smith might seem just another patron of a familiar idea. But the Platonic/Aristotelian version was based on essentially "natural" differences. Its rationale lay in the claim that people had differing talents and dispositions that specialization allowed them to exploit for mutual benefit. The famous (to economists) Ricardian (1817) demonstration of the gains from (international) trade was in the Platonic/ Aristotelian spirit: "comparative advantage," on which the potential for trade depends, requires essentially natural differences of climate. More modern explanations of international trade emphasize other sources of comparative advantage (differing factor proportions or political institutions), but in all such cases the sources of relevant difference lie in exogenous factors. Smith's account requires no natural differences whatsoever-either among persons or regions - to constitute a basis for profitable exchange. For Smith, specialization and exchange are endogenous to the system: the gains from specialization lie not in differences in natural talents but in the "increasing returns" (or economies of scale) that derive from specialization as such.

\footnotetext{
1 The reader should perhaps be warned that this interpretation is somewhat controversial in ways I hope to make clear. It has the virtue that it tracks the first three chapters of The Wealth of Nations-as anyone interested enough to consult those 23 pages can verify.
}

Suppose, for example, that we observe two absolutely identical communities, where all pre-trade relative prices, all individual preferences, and all natural talents are totally identical. The Ricardian model will find no basis for trade-no gains from trade are on offer. But in the Smithian story, there will be potential gains from exchange, because by trading across community boundaries, a more refined division of labor (pattern of specialization) becomes possible with benefits for all parties to the trading nexus. Of course, Smith does not need to deny differences in natural talents or climate or the idea of comparative advantage for his account (though as a matter of fact, he was rather skeptical of claimed differences in natural ability). The critical point is that Smith does not require such things: the primary gains from trade for Smith lie in the productive gains from specialization as such.

Relatedly, although Smith was well aware that both parties to any exchange saw themselves as made better off in the relevant expected sense by that exchange, he did not see those "direct" gains from exchange as the "main game" in the case for exchange. In that sense, Smith differs not just from Ricardo but also from almost all contemporary economists, who have followed the Ricardian model with its assumed "constant returns to scale" (largely for reasons of analytic tractability). ${ }^{2}$ But the Smithian model contains what the standard market models do not-namely, an account of why it is that Malthusian style population growth does not tend to exhaust all productivity gains and ultimately lead to subsistence levels of well-being for all. ${ }^{3}$

To see this, note Smith's observation that "the division of labor is limited by the extent of the market." 4 If the size of the trading nexus expands, then so does the degree of specialization and the average level of material well-being thereby. But this means that an increase in population creates its own production-expansion dynamic. An initial population increase leads to a finer degree of specialization and hence an increase in well-being per head, and thereby a further increase in population (for the essentially Malthusian reasons that Smith fully recognizes). This dynamic interaction generates exactly the picture of increasing population and increasing material well-being for that population that we have in fact witnessed-spectacularly over the last 300 years, and over the previous ten millennia, more gradually and subtly.

\footnotetext{
2 The famous Arrow and Debreu (1954) general equilibrium model and the associated "two basic theorems of welfare economics" also rely on the constant returns model.

${ }^{3}$ Or more accurately, did not do so prior to the widespread availability of reliable contraception

${ }^{4}$ This is the title of Smith's third chapter.
} 


\section{The Puzzle?}

If this history represents a "remarkable" set of facts, what is especially puzzling about them? To be sure, puzzles are in the eye of the beholder, but the particular issue on which PS focuses revolves around the role of trust and trustworthiness in the operation of markets-a feature which Smith's discussion does not foreground. PS's version of Smith's Chapter 3 might well be entitled: "the division of labor is limited by the extent of trust/trustworthiness."

The central idea is this. Every market transaction makes buyers and sellers interdependent in a manner that is somewhat fragile: each party to an exchange has some incentive not to fulfill her part of the bargain-either by explicitly refusing to deliver, or more plausibly to deliver something less than the trading partner expects.

A telling example of the problem is documented in Bee Wilson's delightful account (2008) of the dubious history of food additives through the 19th century. Her story is basically that as the 19th century wore on, people increasingly relied on markets for the supply of their food and drink. In 1800, most people grew their own crops; many baked their own bread, cakes, and pies; many brewed their own beer. Almost all prepared their own meals, from ingredients that they had had a hand in preparing. They could, therefore, have confidence that what they were eating was what they took to be eating. But as the division of labor in the food industry developed, more and more of what they ate was prepared by others, to recipes that others devised, containing elements that they had no direct knowledge of. Buyers were then subject to a newfound uncertainty about the contents of their meals. Sellers could and sometimes would replace flour with chalk, coffee with charcoal, add substances to "improve" the coloring of meat or butter, and so on. Consumers were in this way vulnerable to being "swindled" and sometimes "poisoned" (as Wilson's title implies) in ways that were new and followed directly from the processes of specialization and exchange. Unless consumers trusted the producers of the things they bought, they would not rely on the market for their meat, bread, and beer; they would have to produce these things themselves. And if that were so, the modern economy could not get off the ground. On this view, the primary constraining factor on the operation of "modern economies" was the trust and trustworthiness of the agents who composed the trading nexus. In the absence of such trust, increased numbers would make no difference: the possible gains from specialization could not be realized.

Now, one might think that trustworthiness (trust) would be forthcoming as a matter of course in small close-knit communities: the division of labor relevant to the small tribe (characteristic of man's evolutionary past) would be relatively easily sustained. Each specialist "producer" would be readily observed, and hence fraudulent or otherwise defective production processes easily detected. Moreover, provision of inferior products would soon become common knowledge across the small community: reputation would spread quickly! And opportunities for dissatisfied customers to punish untrustworthy producers would be plentiful. In the small community, any producer would have an incentive to act in a trustworthy fashionand the necessary trust from other members of the community would be rationally forthcoming.

But the situation is quite different in large-scale markets where most of the transactions are anonymous, and/or where the final consumers and producers are separated by a long chain of intermediate producer/traders, where there is little effective scrutiny of producers by consumers, and little scope for punishment of defective products or fraudulent producers apart from refraining from future purchase (and trying a competitor). In dealing with "strangers," there are much lower penalties for acting in an untrustworthy way and hence substantially reduced incentives to be trustworthy - and hence, reduced incentives to trust. And so, the puzzle: the transition from small, largely self-contained communities to the "modern economies" seems to involve a transition from justified trust to trust based largely on faith-a transition from rational trustworthiness to widespread scope for fraud and default. How is this transition possible?

\section{Seabright's Answer?}

I take it that PS's response to this version of the puzzle is to draw it in rather different terms. Here is what I take to be PS's picture: The population is divided into trustworthy and untrustworthy types. There is some characteristic that acts as a signal of trustworthiness-a signal that is "reliable" in the sense that agents who exhibit the characteristic are sufficiently likely to be trustworthy that it pays to trust them in most situations. If this signal were totally reliable, and all situations involved relatively small downside risks, and if the characteristic were very easy to identify, then only trustworthy agents would be trusted, and untrustworthy agents would tend to die out. Though of course as the number of untrustworthy agents becomes very small, it may not pay potential trusters to make even the minimal effort to determine whether an agent was trustworthy or not. And then the community would become vulnerable once again to untrustworthy types.

As the cost of determining whether the relevant characteristic is present or not increases, then a larger number of potential trusters will omit undertaking the test, and the proportion of untrustworthy types in the population will increase. That is, the cost of distinguishing different types, 
the reliability of the test, and the stakes in any interaction will determine the proportion of agents who will take the trouble to check out whether the test is satisfied-and thereby the proportion of untrustworthy types in equilibrium.

Moreover, untrustworthy types that can simulate the characteristic credibly will tend to emerge, and this places pressure on the evolution of ever finer and ever more reliable tests of trustworthiness. There is a kind of dynamic equilibrium in the invention of new signals, more reliable and more robust, as existing signals become vulnerable to imitation by untrustworthy types.

An example offered by PS of this dynamic process is the interesting case of the smile and the laugh. The smile as a gesture of friendship and personal concern is, PS conjectures, an older form of signal, because it can be simulated credibly: the used car salesman can have a winning smile, without necessarily garnering much trust. The "laugh" by contrast is very difficult to simulate: laughter is a much more reliable signal of goodwill and good humor, precisely because it is much harder to simulate laughter than smiling. PS's conjecture: laughter is later on the scene evolutionarily and appears to replace the smile when smiling ceases to be reliable.

Even in the small community, then, the emergence of trustworthiness is no simple business. Even there, some proportion of untrustworthy types will survive, with some propensity for duplicitousness and inventiveness in the appearance of trustworthiness without the reality. The survival of trustworthiness depends not just on the advantages of being trusted but rather more on the capacity of those who are trustworthy to signal their trustworthiness in credible ways.

The puzzle about outsiders, then, revolves less around the issue of whether outsiders were intrinsically less trustworthy than insiders-we might imagine that the proportion of trustworthy types would be roughly the same in all surviving small communities-but rather the issue of whether the signals of trustworthiness that emerge in one community translate to other communities. If, for example, "Orientals" are indeed "inscrutable" to Westerners, then the capacity for a Western trader to detect the trustworthiness credentials of the Oriental trader are impaired-and vice versa. The language of signals breaks down.

But then, what becomes central in assessing the trustworthiness of the stranger is not an agent's own capacity to read the stranger's character, but rather knowledge of what the strangers' own people make of him in the relevant respects (i.e., whether he is a trusted trader in his own community). That is, unless there is good reason to think that the stranger will have an evolved disposition himself to treat strangers and others differently-and this is what PS denies. In short, there is, to be sure, a difference between strangers and non-strangers in terms of the technology of character assessment that is deployed; but that difference does not seem to represent a deep problem in the extension of trust or the expansion of markets.

Note, too, that not all signals of trustworthiness are "psychologically mediated" (as smiling and laughter appear to be). Suppose a new houseoften uses a locution invoking construction company comes to town and there is considerable difficulty in potential buyers assessing the quality (the durability, say) of houses built. How might the new company, lacking an established reputation, persuade buyers that it is not a "fly-by-night" operation, selling off a stack of jerry-built houses and then moving on to the next crop of suckers? One way might be to invest a large amount up-front in location-specific form-perhaps an expensive dedicated office or an expensive local advertising campaign. The double requirement is that the investment be of a kind that will only make economic sense if the firm is to be around for a long time, and that this is a fact readily apparent to customers. Signals of this kind operate via the rationality of agents-but the trustworthiness that they signal seems likely to be an evolved characteristic.

I punctuated the title for this section with a question mark-and I want to conclude the discussion with the two doubts that underlie that punctuation. One relates to whether this is indeed PS's picture. The title of his book serves to suggest that there is a deep puzzle about the networks of trust necessary for the larger market society to operate, and that that deep puzzle revolves specifically around the company of "strangers." The implication is twofold: that trust within the company of non-strangers is relatively unproblematic; and that the divide between trust of strangers and non-strangers is deep and significant.

But the picture I have attributed to PS seems to me to deny both claims. That picture suggests that trust and trustworthiness was a significant problem even within premodern tribal groups: after all, the signaling story requires some proportion of untrustworthy types in ongoing evolutionary equilibrium. And the logic does not suggest any deep additional problems in assessing the trustworthiness of strangers, even though the psychologically mediated mechanisms of signaling seem likely to have some degree of tribal specificity.

None of this is to deny that, as society develops in its modern phase, mistrust of strangers may not have emerged as a rational response to interactive circumstances. Indeed, as I read PS, this is essentially what he thinks. Economic development from 10,000 BC onwards meant the gradual accumulation of transferable assets, with corresponding incentives for collective predation and hence collective protection. As villages sprang up (partly as collective selfprotection devices) they also developed a capacity for aggression. And equally, those individuals who specialized 
in the provision of protection within village communities developed the capacity to appropriate a considerable share of the aggregate surplus for their own use. PS devotes considerable attention to this "Hobbesian" aspect of human development. But this is a late-evolutionary phenomenon, in which the behavior of individual actors is to be explained more by broadly rational prudential calculation than by bits of evolved moral disposition.

The other question mark revolves around whether PS's picture is plausible. He offers two grounds for it: one, that contact with strangers through the evolutionary phase must have been minimal; and second, that skeletal evidence suggests that life in pre-modern society was extremely violent. I am not sure precisely on what basis the first of these claims rests. I know nothing of these things but would have thought that "exchange" of women (either peaceable or via occasional inter-tribal conflict) might have been necessary to prevent an excessive narrowing of the gene pool. And if this is so-if inter-tribal contact was less rare than PS imagines, then the evidence of violent death need not imply intra-tribal savagery.

Of course, this is all somewhat speculative stuff. That is part of what makes it so interesting. Facts are few; and there is much scope for ingenious interpretation and grand reconstruction. And PS's is, as I remarked at the outset, an especially fascinating example.

\section{Three Final Quibbles}

\section{Quibble 1}

When PS characterizes the work that market institutions do in making the "great experiment" (PS's term) possible, he often uses a locution invoking "friendship." These institutions, he says, enable us to "treat strangers as friends" (pp. 1-9). It may seem a trifling anxiety; but this characterization strikes me as mistaken and, more to the point, misleading. Market relations are typically not relations of friendship. Those relations are often anonymous; and, almost always, predominantly self-regarding. The "cooperation" that they manifest is precisely not brokered by an internalization of the interests of the other-in the way one might take friendship to be constituted. Adam Smith (Wealth of Nations I ii 2) puts the point this way: "in civilized society man stands at all times in need of the cooperation and assistance of great multitudes, while his whole life is scarce sufficient to gain the friendship of a few persons." There are, to be sure, norms that govern market relations. And where those norms are not observed, markets do not work well. But these are not norms of friendship! And the virtues they demand are not the virtues of friendship. McCloskey refers to them in the title of his book as the "bourgeois virtues"-precisely to distinguish them from thicker and grander "virtues."

When for example Rawls (1971, p. 4) refers to society as "a cooperative venture for mutual advantage," there is an ambiguity in the use of the term "cooperative." As the Smith quotation indicates, for Smith, cooperation is a descriptive fact about the outcomes that markets produce; it is precisely not a description of the psychological dispositions of market participants. Whatever intentions Rawls had in the use of the phrase, it is clear that many political philosophers have seen the description to involve a certain kind of fellow-feeling among members of society-and to regard the absence of any such fellow-feeling as grounds for criticism, and its presumed presence as soil in which to grow conceptions of distributive justice or the moral authority of national boundaries. The stakes are nonnegligible.

\section{Quibble 2}

PS talks at various points of the phenomenon of "tunnel vision" - and its pros and cons. I am not exactly sure what he means by this term, but it is redolent of a concern that again has something of a history in economics. To refer yet again to Adam Smith (WN I 1 i), "in consequence of the division of labour, the whole of every man's attention comes naturally to be directed towards some one very simple object." And Smith certainly registered ambivalence towards that sharpened focus-emphasizing its implications both for increased productive capacity and for a possible narrowness and dulling of the mind. PS seems to think that "tunnel vision" is implicated in current problems - the global financial crisis among them-but I have to say that the status of the idea in PS's larger explanatory agenda is obscure to me.

\section{Quibble 3}

More generally, I am suspicious of any attempt to draw too close a connection between man's pre-modern evolutionary past and contemporary challenges to the "great experiment." The evolved psychology, under which the division of labor emerged and took initial hold, may not be centrally relevant to the forces that now sustain the market system. As PS himself remarks in relation to the emergence of money, "Understanding how the web of monetary trust was spun in the past is not the same as understanding what holds it in place in the present" (p. 94).

The point surely generalizes. Speculations about our evolutionary past may be fascinating. But they are, in my view, a poor resource for thinking about the global financial crisis, or climate change, or most of the other problems that dog our current world. 


\section{References}

Arrow K, Debreu G (1954) Existence of an equilibrium for a competitive economy. Econometrica 22:265-290

Bee W (2008) Swindled: the dark history of food fraud, from poisoned candy to counterfeit coffee. Princeton University Press, Princeton

Maddison A (2001) The world economy: a millennial perspective. OECD, Paris
McCloskey D (2006) The bourgeois virtues. University of Chicago Press, Chicago

Rawls J (1971) A theory of justice. Belknap/Harvard University Press, Boston

Ricardo D (1817) On the principles of political economy and taxation. John Murray, London

Smith A ([1776] 1981) An enquiry into the nature and causes of the wealth of nations. Liberty Classics, Indianapolis 